\title{
Adsorptive Behavior of Medicinal Product Based Activated Carbon for Removal of Pharmaceutical Active Compounds in Aqueous Phase Redlich-Peterson Studies
}

\author{
NSAR SHERKO OMER ${ }^{1}$, SHAMERAN JAMAL SALIH ${ }^{2 *}$ and HAWAR JALAL SADIQ HAWEZY³
}

${ }^{1,2,3}$ Department of Chemistry, Faculty of Science and Health, Koya University Park, Danielle Mitterrand Boulevard, Koya KOY45, Kurdistan Region of F.R. Iraq.

${ }^{*}$ Corresponding author E-mail: shameran. jamal@ koyauniversity.org

http://dx.doi.org/10.13005/ojc/350244

(Received: September 11, 2018; Accepted: March 15, 2019)

\section{ABSTRACT}

\begin{abstract}
Medicinal product based activated carbon was applied for the sorption of pharmaceutical active compounds in batch and aquatic systems. The MP-AC was characterized utilized X-Ray powder diffraction (XRD), Fourier Transform Infrared Spectroscopy (FTIR) and Scanning Electron Microscopy (SEM). The sorption process was found to be strongly dependent on the $\mathrm{pH}$ of solution which shows maximum sorption efficiency and sorption capacity at lower $\mathrm{pH}(\mathrm{pH}=4)$ of $89.53 \%$ and $\mathrm{qe}=29.35 \mathrm{mg}^{-1} \mathrm{~g}^{-1}$, respectively. Moreover, the $\mathrm{pHpzc}$ also determined using drift method to evaluate the surface charge of the sorbent $(\mathrm{pHpzc}=6.68)$. The sorption mechanism suitably described using a Redlich-Peterson isotherm model and confirmed by the value of chi-square test $\left(X^{2}=0.01905\right)$. The results revealed that the sorption process is spontaneous and more effective at low temperatures.
\end{abstract}

Keywords: Redlich-Peterson model, Medicinal product, Sorption, Aquatic system treatment.

\section{INTRODUCTION}

Countless studies reported the presence of trace amount of pharmaceutical productions in aquatic environment, worldwide, due to discharged into the aquatic bodies that has highly solubility in water ${ }^{1}$. Moreover, many of these active compounds have adverse effect on the mankind. Recent studies detected in traces at ng. $\mathrm{L}^{-1}$ to $\mu \mathrm{g} . \mathrm{L}^{-1}$ levels in surface water and industrial wastewater ${ }^{2,3}$. Many methods has been applied for pharmaceutical wastewater treatments and found that techniques were helpless due to degrading most these PACs. Thus, residual traces remain in the aquatic system ${ }^{4}$. Nevertheless, adsorption technique is a versatile treatment system practiced widely for regulating mobility of pharmaceutical active compound species and their geochemical cycles in the environment ${ }^{5}$. The adsorption utilize activated carbon is ideal for removing small molecular compounds due to the availability of high surface area, and combination of well-developed pore structure and surface functional group properties ${ }^{5,6}$.

This is an Open Access article licensed under a Creative Commons license: Attribution 4.0 International (CC- BY). Published by Oriental Scientific Publishing Company @ 2018 
Based on literature, ibuprofen, a nonsteroidal and anti-inflammatory, is one of the most common drugs found in water ${ }^{6}$ the latter been detected in the effluents from several sewagetreatment plants at concentrations up to $24.6 \mu \mathrm{g} /$ $L^{7}$ possibly presenting a potential hazard for human health ${ }^{11}$. Furthermore, virtually all drugs especially in large doses or when taken over long periods, can initiate a toxic condition ${ }^{8}$. The major principles applied in the emergency treatment of accidental poisoning drug are dilution, emesis and adsorption. Many types of adsorbents such as kaolin ${ }^{21}$, attapulgite and betonies in the prevention of further adsorption of drugs are recognizing in clinical practice and environmental treatment. Adsorption of ibuprofen was studied using activated carbon ${ }^{23}$.

Meanwhile, Activated carbon, in a powdered form, should be in every medicine cabinet and first aid kit. It is also known as activated charcoal ${ }^{12}$. It is used around the world as a universal antidote for hundreds of poisons, including arsenic, mercury, pesticides, strychnine, warfarin, hemlock, E. coil endotoxin, and gasoline. Over 5,000 chemicals, drugs, plant and microbial toxins, allergens, venoms, and wastes are effectively neutralized by activated charcoal, when it is given in sufficient quantities. Activated charcoal is also an effective detox for practically any drug overdose if administered in time ${ }^{15}$.

Here we attempt to find a new sorbent to act as physical antidotes in treatment of poisoning if the drug is taken in quantities higher than the recommended dosages, hence to understand that the effect of the some parameters on the sorption process was studied.

Finally, various isotherms (Langmuir, Freundlich, and Redlich-Peterson) and parameters have been examined such as effect of initial IBU solution, $\mathrm{pH}$, contact time, ionic strength and temperature was investigated of loaded IBU onto medicinal products based activated carbon (MP-AC).

Table1: Physico-chemical properties of pharmaceutical active compound- ibuprofen (PAC-IBU) ${ }^{18,25}$

\begin{tabular}{lllll}
\hline $\begin{array}{l}\text { Molecular } \\
(\mathrm{mg} / \mathrm{ml})\end{array}$ & $\begin{array}{c}\text { Structure } \\
\text { CAS No. }\end{array}$ & $\begin{array}{c}\mathrm{MW} \\
(\mathrm{g} / \mathrm{mol})\end{array}$ & $\mathrm{pKa}$ & $\begin{array}{c}\text { Water } \\
\text { solubility }\end{array}$ \\
\hline
\end{tabular}

\section{MATERIALS AND METHODS}

\section{Materials}

All reagents used were of analytical purity, Ibuprofen (HIKMA), hydrochloric acid $37 \%$ (Analar), potassium chloride (Aldrich), sodium hydroxide(Merk), sodium hydrogen carbonate (Sigma -Aldrich), potassium hydrogen phthalate (Merck) and potassium hydrogen phosphate (Merck) were used to prepare the buffer solutions with different $\mathrm{pH}$ values, In addition . All working solutions were prepared by diluting the stock solutions with deionized water.

\section{Preparation of stock solution}

The stocks were prepared by dissolving $0.1 \mathrm{~g}$ of ibuprofen in $100 \mathrm{ml}$ using sensitive weight balance (HTCE $3000 \mathrm{~g}$ ). The solution stirred thoroughly with a magnetic stirrer overnight, until a well-mixed solution achieved with all IBP dissolved ${ }^{19}$. Solutions of known initial concentrations were then created from the stock solution for each experimental treatment. This was done by pipetting the stock solution into vials with ultrapure water. The $\mathrm{pHs}$ of the samples were adjusted by the drop-wise addition of $\mathrm{HCl}$ or $\mathrm{NaOH}$ and the use of an $\mathrm{pH}$ meter ( $\mathrm{pH} / \mathrm{lon} 510)$.

\section{Batch adsorption experiments}

The adsorption of PAC-IBU and removal efficiency by the selected activated carbon examined utilizing the batch equilibrium method. Different amount of sorbent has been tested $(20,40$, 60,80 and $100 \mathrm{mg}$ ) then suspended in the IBU solution and shaken until equilibrium time reached. After filtration, the amount of adsorbed PAC-IBU molecules were calculated from the variation between the initial and final concentration (Nonadsorbed molecules) of ibuprofen, measured by UV-Visible spectrophotometer at a wavelength of $222.8 \mathrm{~nm}^{7,13,22}$. On the other hand, in order to study the effect of temperature on the adsorption process the batch operated at different temperatures, also various solution $\mathrm{pH}$ have been conducted $(\mathrm{pH}=3-12)$. The uptake of PAC-IBU per unit mass of sorbent was then determined through mass-balance calculations ${ }^{11,20}$.

$q_{e}=C_{o}-C_{e} \frac{V}{W}$

Where $\mathrm{q}_{e}=$ is the amount of adsorbed PAC-IBU $(\mathrm{mg} / \mathrm{g}), \mathrm{C}_{\mathrm{o}}=$ Initial concentration $\left(\mathrm{mgl}^{-1}\right)$, 
$\mathrm{C}_{\mathrm{e}}=$ equilibrium concentration $\left(\mathrm{mgl}^{-1}\right), \mathrm{W}=$ Mass of adsorbent $(\mathrm{mg})$ and $\mathrm{V}=$ Solution volume (ml). However, the removal percentage was determined using the equation below (Yaneva and Koumanova, 2006):

$\% R=\frac{C_{o}-C_{e}}{C_{o}} \times 100$

Where $\mathrm{C}_{\mathrm{o}}$ and $\mathrm{C}_{\mathrm{e}}=$ Initial and final PAC-IBU concentration $\left(\mathrm{mgl}^{-1}\right), \mathrm{R} \%=$ removal percentage. Meanwhile, scanning electron microscopy (SEMmodel HTCE $3000 \mathrm{~g} 0.01 \mathrm{~g}$ ), FT-IR (SHIMADZU), XRD (Rigaku Mini) have been applied for the loaded IBU for better understanding the adsorption process.

\section{RESULTS AND DISCUSSION}

\section{Characterization}

The characteristic of FT-IR spectra which providing the essential information about the adsorption of PAC-IBU onto selected activated carbon. On the other hand, an intensity band was increased presenting maxima at $1012.99 \mathrm{~cm}^{-1}$ and $1384.52 \mathrm{~cm}^{-1}$ assigned to C-O stretching in ether or ester groups due to bleaching ${ }^{17,26}$. In accordance of Fig. 1 ( $a$ and $b$ ) the bleaching treatment a new broad band present in the $3200 \mathrm{~cm}^{-1}$ and $3600 \mathrm{~cm}^{-1}$ due to the $\mathrm{O}-\mathrm{H}$ stretching vibration of chemisorbed water and phenolic group ${ }^{22}$. In addition, the peak centered at $1639.17 \mathrm{~cm}^{-1}$ only noticed after loading of PAC$\mathrm{IBU}$ is assigned to the $\mathrm{C}=\mathrm{O}$ stretching vibration of ester, ketone and/or carboxylic group. Finally, all spectra observed at $1580 \mathrm{~cm}^{-1}$ and $1618 \mathrm{~cm}^{-1}$ as signed to $\mathrm{C}=\mathrm{C}$ stretching formulizations of aromatic rings or $\mathrm{C}=\mathrm{O}$ stretching vibration conjugated with aromaticrings $^{18}$.

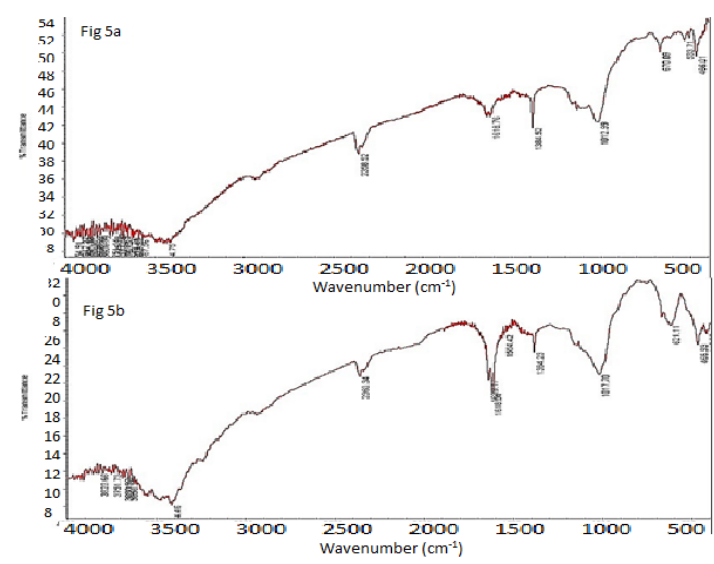

Fig.1. FT-IR spectrum of PAC-IBU removal
The XRD pattern Fig. 2 showed broad diffraction peak which is centered at $2 \theta=21^{\circ}$ and $2 \theta=42^{\circ}$. This illustrated that the medicine productbased activated carbon (MP-AC) was preponderantly amorphous as the presence of two broad Bragg were clearly demonstrated that the MP-AC is turbostratic structure and amorphous ${ }^{23,27}$. It has clearly seen from Fig. 2 a the diffraction does not have any sharp peaks throughout the range of 2-theta, hence proposed that MP-AC does not possess a crystalline nature ${ }^{19}$. Nevertheless, amorphous-like structure with broad peak is necessary to examine the hybridization of the electrons of an atom of carbon Raman spectroscopy ${ }^{10}$.

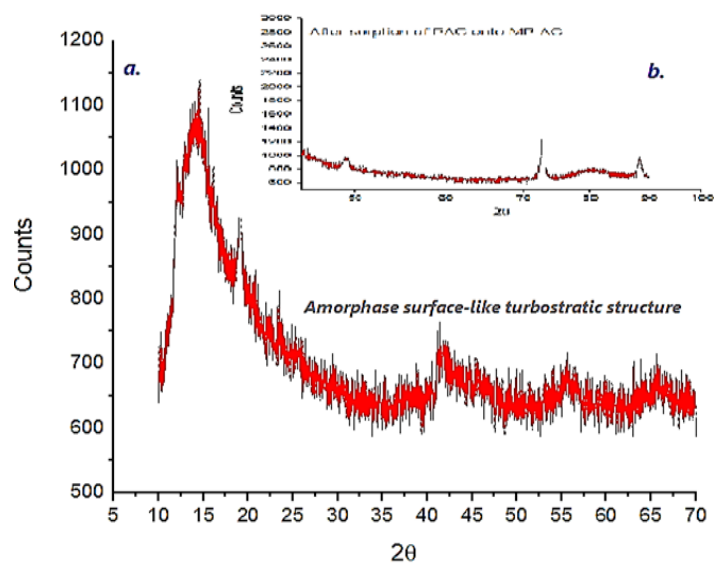

Fig. 2. X-ray pattern of MP-AC (a) before adsorption (b) after adsorption

The broadened peak at $2 \theta=42^{\circ}$ might be with the increasing temperature also increase in the intensity of the amorphous halo peak. Besides, maximum becomes more pronounced and moves to $43^{\circ}-44^{\circ}$, which is characteristic of graphite and associated with the processes of graphitization of the organic-components and the formation of the nanocrystalline-structure of the matrix ${ }^{14,31}$. Meanwhile, Fig. 3b. showed the diffractograms after the sorption process which easily understood that the adsorbate molecules successfully loaded onto the amorphouslike graphite sorbent surface. On the other hand, in both vividly recommended that the sorption system uniquely results change in the surface structure of the sorbent. Finally, the analyzed pattern of X-ray diffraction was also confirmed elsewhere ${ }^{12,25}$.

\section{SEM-Morphology}

The topographical information and surface structure of selected activated carbon 
after sorption process were achieved utilizing scanning electron microscopy (model NORAN) at an electron acceleration voltage of $25 \mathrm{kV}$. The sample coated by a thin layer-gold before scanning to make conductive using splutter coater. Fig. $3 a$ showed the porous surface of the sorbent involved large holes, cracks, channels and full of cavities ${ }^{2,27}$, mostly irregular with some smooth surfaces also can be observed. Whereas, Fig. 3b. elucidate the successful loaded of the adsorbate molecules which well-diffused in the pores of the sorbent surface then were aggregated-well via natural entrapped and governed by electrostatic force. As a result, it has easily visualized the dark spots, which can demarcate as a sign for efficient sorption system. In other words, the morphological study confirmed highly heterogeneous attached in the dark holes with various-classes of PAC molecules ${ }^{21}$.

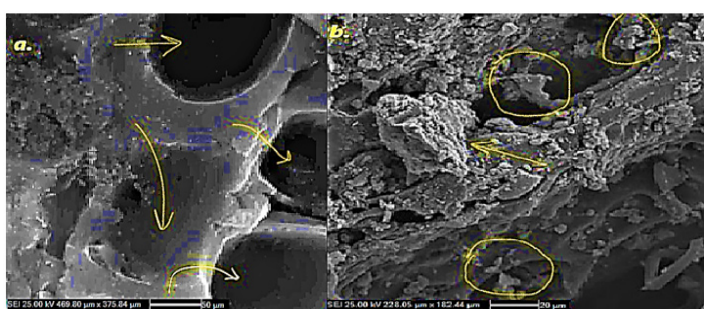

Fig. 3. SEM-micrograph of (a) before sorption, (b) after sorption of PAC onto MP-AC

\section{Optimization of operation parameters in a batch system \\ Effect of contact time}

One of the significant key factor for pharmaceuticals removal is study of contact time, the sorption process conducted at different contact times using selected activated carbon. Nevertheless, the adsorption of PAC-IBU rapidly increased with the raise of contact time at initial stages, on the other hand, gradually approached until reached equilibrium. Meanwhile, the rapid kinetics of the sorption process at initial stages perhaps attributed to high availability of binding sites ${ }^{24,25,26}$. However, chemical attractions diffusion and other driving forces may take place. Hence, the adsorption rate decreased due to less porous as a result of the migration of pharmaceutical product. In addition, the adsorption efficiency reached maximum removal at $90 \mathrm{~min}(89.53 \%)$ and adsorption capacity was $36.72(\mathrm{mg} / \mathrm{g})$. Also, after $120 \mathrm{~min}$, the rate of removal of pharmaceuticals is constant indicate the equilibrium and the non-availability of sorption sites. The maximum uptake of drugs onto MP-AC observed at $90 \mathrm{~min}^{32}$.

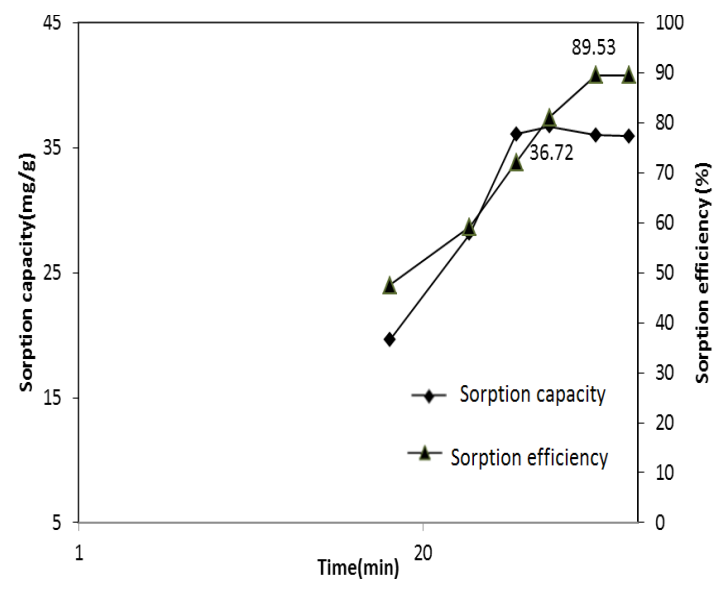

Fig. 4. Effect of contact time of IBU sorption onto MP-AC

\section{Effect of $\mathrm{pH}$ on the removal process}

The $\mathrm{pH}$ of the solution is one of the important factors in controlling the adsorption process and particularly on the amount of adsorbed molecules by controlling the surface charge of the sorbent and by this way shows adsorbate-adsorbent electrostatic interaction (Oke et al., 2008). The obtained data showed highest amount of adsorbed molecules $\left(q_{e}=29.35 \mathrm{mg} / \mathrm{g}\right)$ at $\mathrm{pH} 4$, Fig. 5 confirmed that as solution of $\mathrm{pH}$ increased to 12 , adsorption capacity gradually decreased reaching minimums value at higher $\mathrm{pH}$.

Thus, the ionization of PAC-IBU affected by solution $\mathrm{pH}$ based on its ionization $\mathrm{pKa}=4.9$, its expected that $50 \%$ of IBU become deprotonated at higher $\mathrm{pH}$ when $(\mathrm{pH}>\mathrm{pKa})$ similar data reported elsewhere $^{8,25}$

Overall, the fully or partially deprotonated surface charge due to an increase of $\mathrm{pH}$, therefore a loss of positive charge may build up of negative charge ${ }^{17}$. Also, as shown in Fig. 6 the point of zero charge (pHpzc) has been determined according to methods that reported from litterateurs and was found to be $6.68^{23}$.

At the time adsorption occurs at $\mathrm{pH} 9$ $(\mathrm{pH}>\mathrm{pKa}$ ) the anionic form of PAC-IBU is dominant in solution and besides surface charge on the activated carbon is negatively charge when the solution $\mathrm{pH}$ is greater than pHpzc. Hence, the adsorption capacity 
is reduced due to electrostatic repulsion between the net surface charge of MP-AC and deprotonated PAC-IBU. In addition, at lower $\mathrm{pH}$ value, the net surface charge on MP-AC is positive and PACIBU is essentially non-dissociated. Consequently, the adsorption were enhanced due to the fact of repulsive electrostatic interactions are reduced ${ }^{23,27}$.

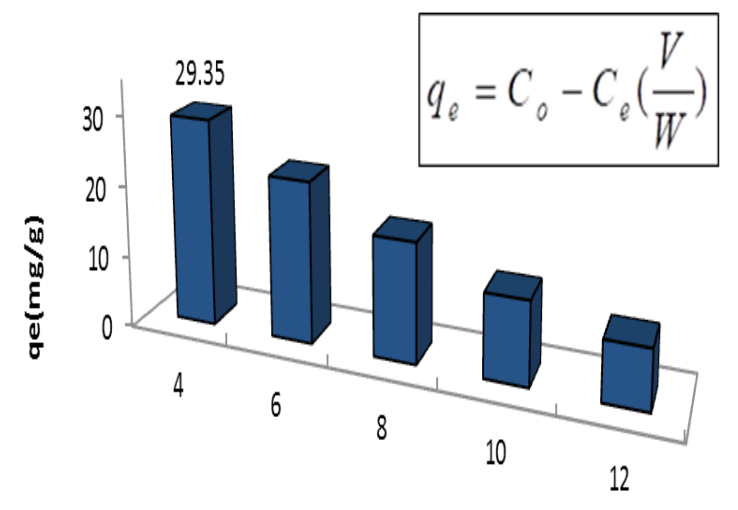

$\mathrm{pH}$

Fig. 5. The influence of solution $\mathrm{pH}$ onto IBU removal

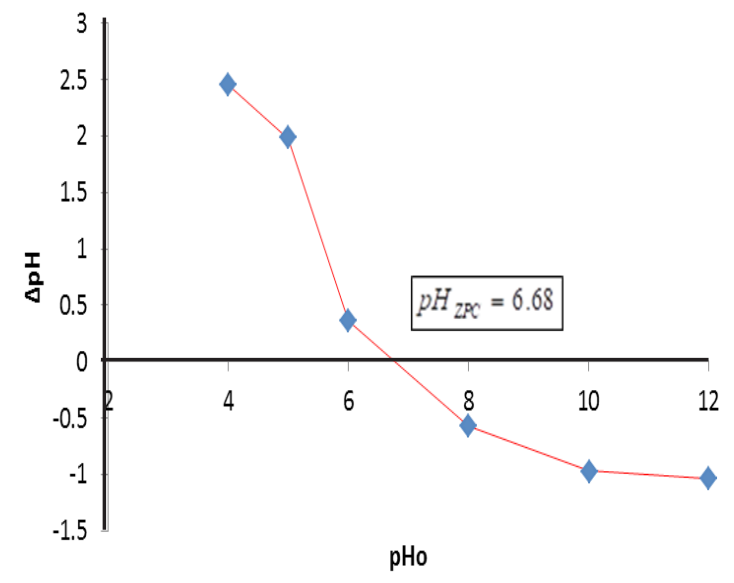

Fig. 6. Point of zero charge of the MP-AC-Sorbent

\section{Modeling of sorption isotherm}

In this work various isotherm models were utilized for PAC-IBU removal from aquatic media and/ or to relize the mechanism of the sorption system from physico-chemical view. Hence, constants of isotherms are commonly used in designing of the equilibrium data based on the hybird isotherm incoorporates three parameters into one emprical equation by combining both Freundlich and Langmuir models resulted mixed isotherm model as known by Redlich-Peterson model ${ }^{24}$. The mathematical expression of the cominations are listed in equations 3 and 4 . Additionally, the sorption mechanism is a mix and does not follow ideal monolayer adsorption.

Freundlich-Langmuir equation:

$q_{e}=q_{m} \frac{\left(K_{E} C_{e}\right)^{n}}{1+\left(K_{E} C_{e}\right)^{m}}$

Redlich -Peterson equation:

$q_{e}=\frac{K_{R} C_{e}}{1+a_{R} C_{e}^{\mathrm{b}}}$

However, in this work the Chi-square test has been evaluated using the mathematical expression below ${ }^{2,18}$ :

$x^{2}=\sum_{i=1}^{p} \frac{\left(q_{\text {meas }}-q_{\text {cal }}\right)^{2}}{q_{\text {meas }}}$

Where $p$ denotes the number of experimental data, $q_{\text {calc }}$ is calculated equilibrium concentration, $\mathrm{q}_{\text {meas }}$ is measured equilibrium concentration and $q$ is the average of $q_{\text {calc }}$. The feature of utilizing the Chi-square test was the comparison of all isotherms on the same Abscissa and ordinate ${ }^{19}$. When the measuring data from the model were similar to the experimental data, $\mathrm{X}^{2}$ would be a small number or vice versa. Moreover, the equilibrium data and constants of the above models are tabulated in Table 2.

Table 2: Constants and parameters of isotherm modeling obtained by calculation of the liner form

\begin{tabular}{|c|c|c|c|c|c|c|c|c|}
\hline \multirow[b]{2}{*}{ Models } & \multicolumn{7}{|c|}{ Isotherm Constants and Prameter's } & \multirow[b]{2}{*}{$\mathrm{X}^{2}$} \\
\hline & $A_{R}$ & $\mathrm{~K}_{\mathrm{R}}$ & $\beta$ & $\mathrm{K}_{\mathrm{F}}$ & $1 / n$ & $Q_{m}$ & $\mathrm{~K}_{\mathrm{L}}$ & \\
\hline $\begin{array}{l}\text { Redlich } \\
\text {-Peterson }\end{array}$ & 48.3071 & 0.5940 & 24.007 & - & - & - & - & 0.01905 \\
\hline Freundlich & - & - & - & 1.8693 & 0.17558 & - & - & 0.11837 \\
\hline Langmuir & - & - & - & - & - & 23.4907 & 0.3782 & 1.49170 \\
\hline
\end{tabular}

Meanwhile, from Fig. 7 and Table 3. utlized MP-AC explained well enough by both observed that the sorption capacity of PAC-IBU Freunflich and Redlich-Peterson models which have 
highest coefficient of determination $\mathrm{R}^{2}=0.9657$ and $R^{2}=0.9398$ respectively. This might be availability of hetrogeneous surface with several classes of the sorbent-porosity caused physically holding of IBU molecules from the liquid phase ${ }^{24,32}$. Also, Table 2 revealed that the values of calcutaing small values of $\mathrm{X}^{2}$ and constants regarding to the sorption intensity (n) which is smaller than $1(1 / n=0.17558)$ that both freundlich and Redlich-Peterson confirmed that the MP-AC has high capaibility for PAC-IBU removal within physically interactions ${ }^{18,19}$. In addition, the linearized Langmuir shows the higher valeus of the $\mathrm{X}^{2}$ (1.49170) and lower $R^{2}(0.8085)$ which indicated that the Langmuir isotherm is not approparate model to use.
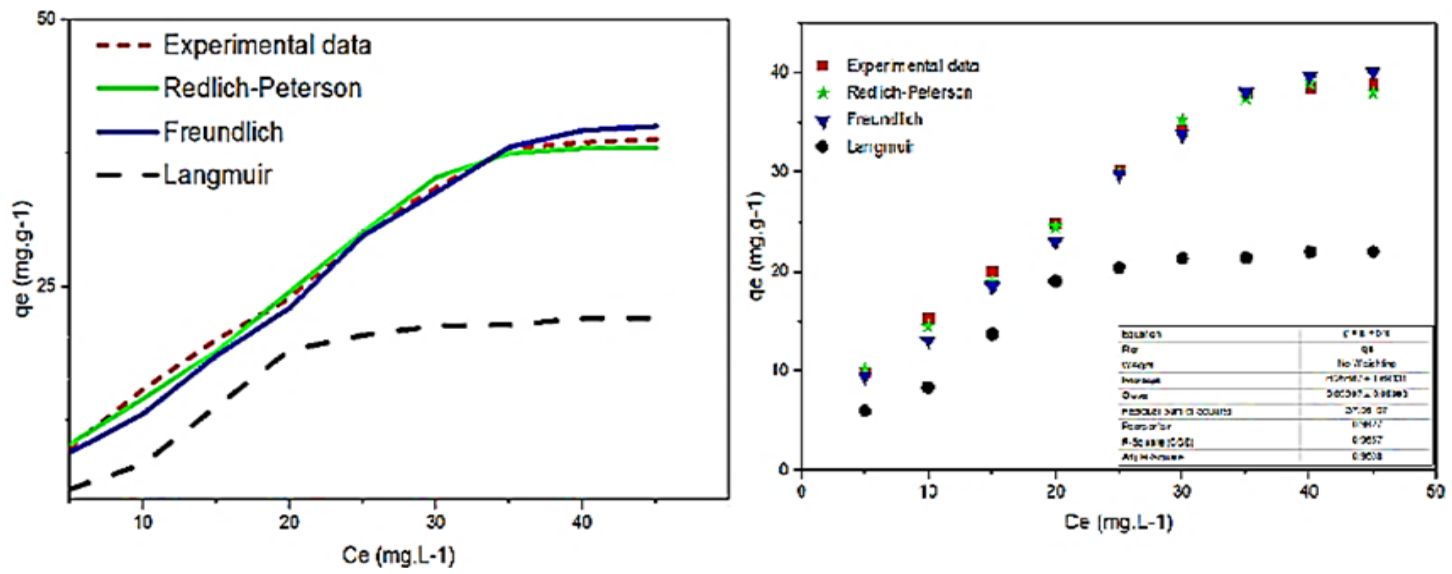

Fig. 7. Redlich-Peterson, Freundlich and Langmuir models for PAC-IBU removal

Table 3: The coefficient of determination for the isotherm models

\begin{tabular}{lcccc}
\hline Prarameter & Value & Fixed & Error & $\mathrm{R}^{2}$ \\
\hline Experimental Data & & & & \\
Intercept & 8.55889 & $\square$ & 1.87447 & 0.94993 \\
Slope & 0.76773 & $\square$ & 0.06662 & \\
Redlich-Peterson & & & & \\
Intercept & 8.16889 & $\square$ & 2.08468 & 0.93986 \\
Slope & 0.77493 & $\square$ & 0.07409 & \\
Freundlich & & & & \\
Intercept & 6.25667 & $\square$ & 1.68331 & 0.9657 \\
Slope & 0.83987 & $\square$ & 0.05983 & \\
Langmuir & & & & \\
Intercept & 6.92944 & $\square$ & 2.11638 & 0.80857 \\
Slope & 0.409 & $\square$ & 0.07522 & \\
\hline
\end{tabular}

\section{Evaluation of thermodynamic parameters}

In order to evaluate the thermodynamic parameters and effect of temperature as well on the sorption process, the sorption experiments were achieved at varied temperatures $(298,303,313$ and 323) K. As can be seen from Fig. 8 the raise of temperature affect negatively on the amount of qe $(\mathrm{mg} / \mathrm{g})$ and the percent of removal which decrease from $89.3 \%$ at $298 \mathrm{~K}$ to $49.07 \%$ at $323 \mathrm{~K}$. Additionally, as temperature increases the sorption capacity

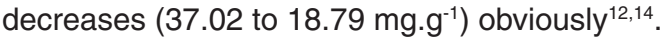

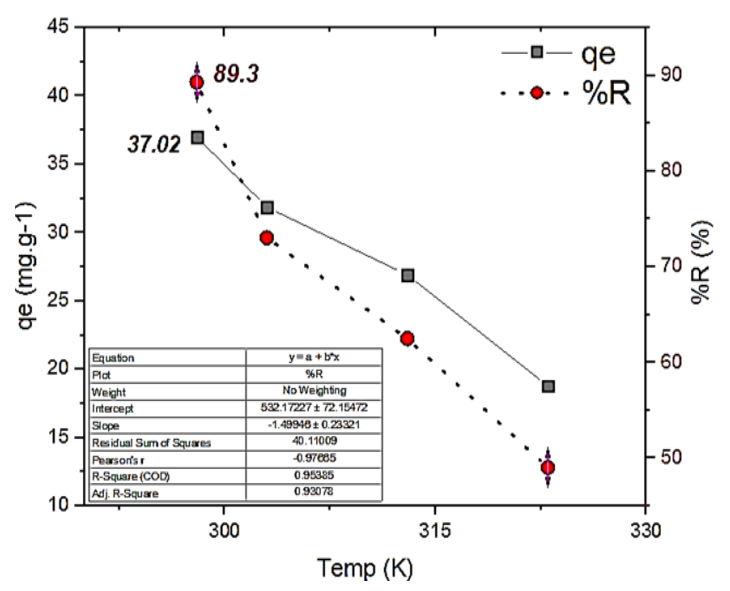

Fig. 8. Effect of temperature on the sorption of PAC-IBU onto MP-AC (Initial conc. 100mg.L-1, pH 4 and dosage $250 \mathrm{mg}$ )

Here, we observed that the increment of temperature certainty caused the destabilization of the physically binding forces and this clearly understood there is an ideal value to encourage the sorption of pharmaceutical products.

However, in order to measure the heat of sorption, which is the specification, that distinguishes the physisorption and chemisorption thermal process. In addition, heat of adsorption elucidated by Gibbs-Helmholtz ${ }^{2}$. 
$\Delta G^{o}=\Delta H^{o}-T \Delta S^{o}$

$\mathrm{DG}^{\circ}=-T R \ln \mathrm{K}_{\mathrm{c}}$

The Enthalpy change $\left(\Delta \mathrm{H}^{\circ}\right)$ and Entropy change $\left(\Delta S^{\circ}\right)$ (i.e. heat of adsorption) are related with the Gibbs free energy by the equation

$\ln K_{c}=\frac{\Delta S^{\circ}}{R}-\frac{\Delta H^{\circ}}{R T}$

$K_{c}=\frac{q_{e}}{C_{e}}$

$K_{c}=\frac{C_{e} V}{M\left(C_{o}-C_{e}\right)}$

Where, Kc equilibrium constant, $\Delta$ Go Gibbs free energy $\left(\mathrm{J} \mathrm{mol}^{-1}\right), \Delta \mathrm{S}^{\circ}$ entropy $\left(\mathrm{KJ} \mathrm{mol}^{-1} \mathrm{~K}^{-1}\right), \Delta \mathrm{H}^{\circ}$ enthalpy $\left(\mathrm{KJ} \mathrm{mol}^{-1}\right)$, T absolute temperature $(\mathrm{K}), \mathrm{C}_{0}$ initial concentration of the IBU, $C_{e}$ equilibrium concentration of the PAC-IBU, $V$ volume of solution, $M$ mass of the MP-AC, R gas constant $\left(8.314 \mathrm{~J} \mathrm{~mol}^{-1} \mathrm{~K}^{-1}\right)$.

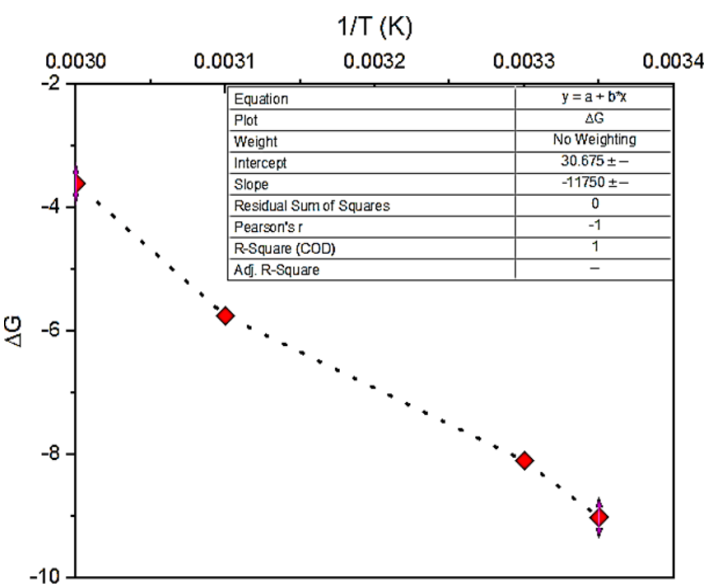

Fig. 9. Plot of Gibb's free energy change versus Temp for sorption of pharmaceutical products

In conductance of Fig. 9, the negative value $\Delta \mathrm{G}^{\circ}$ confirmed the feasibility and spontaneous sorption process. Further, the entropy $\Delta S^{\circ}$ sorption and the heat of sorption $\Delta \mathrm{H}^{\circ}$ on MP-AC were determined graphically from slop and intercept in a function of the inverse of the temperature in $\mathrm{K}$ of the medium ${ }^{6,20}$. As can be seen from Table 4, the positive value of $\Delta \mathrm{H}^{\circ} 7.94 \mathrm{~kJ} \mathrm{~mol}^{-1}$ indicates that the adsorption of PAC-IBU on the selected activated carbon is an endothermic process. Meanwhile, the positive value of $\Delta S^{\circ} 0.028 \mathrm{~kJ} \mathrm{~mol}^{-1} \mathrm{~K}^{-1}$ agreed to an increment in randomness at the solid-interface with some structural changes in the adsorbent and adsorbate ${ }^{1,15}$.

Finally, in this work the $\Delta G^{\circ}$ values are in the range of -3.6 to $-9.02 \mathrm{~kJ} \mathrm{~mol}^{-1}$ confirming that the sorption of drug is mainly physical process.

Table 4: Iso Gibbs free energy change, enthalpy heat of sorption of pharmaceutical active products

\begin{tabular}{cccccc}
\hline$\Delta \mathrm{S}^{\circ}\left(\mathrm{kJ} \mathrm{mol}^{-1} \mathrm{~K}^{-1}\right)$ & $\Delta \mathrm{H}^{\circ}\left(\mathrm{kJ} \mathrm{mol}^{-1}\right)$ & \multicolumn{4}{c}{$\Delta \mathrm{G}^{\circ}\left(\mathrm{kJ} \mathrm{mol}^{-1}\right)$} \\
\hline 0.028 & 7.94 & $298 \mathrm{~K}$ & $303 \mathrm{~K}$ & $313 \mathrm{~K}$ & $323 \mathrm{~K}$ \\
& & -9.02 & -8.1 & -5.75 & -3.6 \\
\hline
\end{tabular}

\section{CONCLUSION}

In the present study, new model approaches have been examined the sorption of pharmaceutical active products in aqueous solutions. Besides the acid $\mathrm{pH}$ solutions encouraged the sorption process achieved by electrostatic-interactions and the maximum uptake observed at $\mathrm{pH} 4$ (percentage $\mathrm{R}=89.3$ ). In accordance of the equilibrium data the Redlich- Peterson model showed the best fit within lowest Chi-square test $\left(X^{2}=0.019\right)$ followed by Freundlich model $\left(X^{2}=0.11\right)$. In turn, the SEM micrographs confirmed that the sorption process successfully loaded which shows the heterogeneous surface covered by adsorbate molecules with several classes of sorbent-porosity. Besides, the XRDanalysis confirmed that the MP-AC preponderantly was turbostratic, in accordance to the range of 2-theta which proposed that the sorbent does not have a crystalline nature. On the other hand, varied thermodynamic parameters have also been examined and found that the sorption process was endothermic, feasible and spontaneous in nature, the increment of randomness at the solid-interface has confirmed by the value of entropy $\left(\Delta S^{\circ}=0.028\right.$ $\mathrm{KJ} \mathrm{mol}^{-1} \mathrm{~K}^{-1}$ ). Finally, the information that gained from this work could help for giving remarkable details on the transport and maintenance of pharmaceutical active compounds in subsurface environment.

\section{ACKNOWLEDGMENT}

This research did not receive any specific grant from funding agencies in the public, commercial, or not-for-profit sectors. 


\section{REFERENCES}

1. Baccar, R.; Sarrà, M.; Bouzid, J.; Feki, M. and Blánquez, P., Removal of pharmaceutical compounds by activated carbon prepared from agricultural by-product, Chemical engineering journal., 2012, 211, 310-317.

2. Rashid, B. Z.; Omar, R. A. \& Salih, S. J., Characterization and Antimicrobial Efficiency of Silver Nanoparticles Based Reduction Method, International Journal of Current Microbiology and Applied Sciences., 2016; 5(8), 802-810.

3. Bercu, J. P.; Parke, N. J.; Fiori, J. M. \& Meyerh off, R. D., Human health risk assessments for three neuropharmaceutical compounds in surface waters, Regulatory Toxicology and Pharmacology., 2008, 50, 420-427.

4. Carrott, P. \& Carrott, M. R., Lignin-from natural adsorbent to activated carbon: a review, Bioresource technology., 2007, 98, 2301-2312.

5. Cermola, F.; Dellagreca, m.; lesce, m. R.; Montella, s.; Pollio, a. \& Temussi, F., A mild photochemical approach to the degradation of phenols from olive oil mill wastewater, Chemosphere., 2004, 55, 1035-1041.

6. El-rahman, K. A.; El-kamash, A.; El-sourougy, M. \& Abdel-moniem, N., Thermodynamic modeling for the removal of $\mathrm{C}^{\mathrm{s}+}, \mathrm{Sr}^{2+}, \mathrm{Ca}^{2+}$ and $\mathrm{Mg}^{2+}$ ions from aqueous waste solutions using zeolite A, Journal of radioanalytical and nuclear chemistry., 2006, 268, 221-230.

7. Faraj, H. R. \& Salih, S. J., Potential of PistachioHard Shell Based ThiosemicarbazoneAcetophenone for $\mathrm{Pb}^{2+}$ Metal Sorption: Kinetic Studies, Isotherms Modeling and Optimization, Journal of zankoy slemany., 2017, 19(1), 133-148.

8. Hernando, M.; Mezcua, M.; FernándezAlba, A. \& Barceló, D., Environmental risk assessment of pharmaceutical residues in wastewater effluents, surface waters and sediments, Talanta., 2006, 69, 334-342.

9. Gazi, M. and Shahmohammadi, S., Removal of trace boron from aqueous solution using iminobis-(propylene glycol) modified chitosan beads, Reactive and Functional Polymers., 2012, 72(10), 680-686.

10. Guedidi, H.; Reinert, L.; Soneda, Y.; Bellakhal, N. and Duclaux, L., Adsorption of ibuprofen from aqueous solution on chemically surface-modified activated carbon cloths, Arabian Journal of Chemistry., 2017, 10, S3584-S3594.

11. Kyzas, G. Z.; Koltsakidou, A.; Nanaki, S. G.; Bikiaris, D. N. \& Lambropoulou, D. A., Removal of beta-blockers from aqueous media by adsorption onto graphene oxide, Science of the Total Environment., 2015, 537, 411-420.

12. Lindqvist, N.; Tuhkanen, T. \& Kronberg, L., Occurrence of acidic pharmaceuticals in raw and treated sewages and in receiving waters, Water Research., 2005, 39, 2219-2228.

13. Margot, J.; Kienle, C.; Magnet, A.;Weil, M.; Rossi, I.; De alencastro, I. F.; Abegglen, c.; Thonney, d.; Chèvre, n. \& Schärer, M., Treatment of micropollutants in municipal wastewater: ozone or powdered activated carbon? Science of the total environment., 2013, 461, 480-498.

14. Mittal, A.; Jhare, D. \& Mittal, J., Adsorption of hazardous dye Eosin Yellow from aqueous solution onto waste material De-oiled Soya: Isotherm, kinetics and bulk removal, Journal of Molecular Liquids., 2013, 179, 133-140.

15. Nanaki, S. G.; Kyzas, G. Z.; Tzereme, A.; Papageorgiou, M.; Kostoglou, M.; Bikiaris, D. N. \& Lambropoulou, D. A., Synthesis and characterization of modified carrageenan microparticles for the removal of pharmaceuticals from aqueous solutions, Colloids and Surfaces B: Biointerfaces., 2015, 127, 256-265.

16. Nowicki, P.; Kuszyaska, I.; Przepiórski, J. \& Pietrzak, R., The effect of chemical activation method on properties of activated carbons obtained from pine cones, Central European Journal of Chemistry., 2013, 11, 78-85.

17. Oke, I.; Olarinoye, N. \& Adewusi, S., Adsorption kinetics for arsenic removal from aqueous solutions by untreated powdered eggshell, Adsorption., 2008, 14, 73-83.

18. Oladipo, A.A. and Gazi, M., Fixed-bed column sorption of borate onto pomegranate seed powder-PVA beads: a response surface methodology approach, Toxicological \& Environmental Chemistry., 2014, 96(6), 837-848.

19. Olorundare, O.; Krause, R.; Okonkwo, J. \& Mamba, B., Potential application of activated carbon from maize tassel for the removal of heavy metals in water, Physics and Chemistry of the Earth, Parts A/B/C., 2012, 50, 104-110.

20. Ranjbar, M., Malakooti, E. and Sheshmani, 
S., Synthesis and characterization of mercury (II) complexes containing 2, 9-dimethyl-1, 10-phenanthroline by sonochemical method, Journal of Chemistry., 2012, 2013.

21. RA, J. S.; OH, S.-Y.; LEE, B. C. \& KIM, S. D., The effect of suspended particles coated by humic acid on the toxicity of pharmaceuticals, estrogens, and phenolic compounds, Environment international., 2008, 34, 184-192.

22. Rivera-Jiménez, S. M.; Méndez-gonzález, S. \& Hernández-maldonado, A., Metal $\left(\mathrm{M}=\mathrm{Co}^{2+}\right.$, $\mathrm{Ni}^{2+}$, and $\mathrm{Cu}^{2+}$ ) grafted mesoporous SBA-15: Effect of transition metal incorporation and $\mathrm{pH}$ conditions on the adsorption of Naproxen from water, Microporous and Mesoporous Materials., 2010, 132, 470-479.

23. Saber-samandari, S.;Saber-samandari, S.\& Gazi, M., Cellulose-graft-polyacrylamide/hydroxyapatite composite hydrogel with possible application in removal of $\mathrm{Cu}$ (II) ions, Reactive and Functional Polymers., 2013, 73, 1523-1530.

24. SALIH, S. J., Removal of Basic Dyes from Aqueous Solution by Chloroacetic Acid Modified Ferula Communis Based Adsorbent: Thermodynamic and Kinetic Studies, Eastern Mediterranean University (EMU)-Doau Akdeniz Üniversitesi (DAÜ)., 2014.

25. Salih, S. J.; Anwer, S. S. \& FARAJ, R. H., A Biosorption of Mercury from Wastewater Using Isolated Aspergillus Sp. Modified 1, 10Phenanthroline: Hill Isotherm Model, Science Journal of University of Zakho., 2017, 5, 288-295.

26. Salih, S. J. \& Rashid, B., Cranberry Stem as an Efficient Adsorbent and Eco-Friendly for Removal of Toxic Dyes from Industrial Wastewater. Physico
Studies, International Journal of Pharmaceutical Chemistry., 2015, 5, 207-17.

27. Salih, S. J. \& Smail, A. K., Synthesis, characterization and evaluation of antibacterial efficacy of zinc oxide nanoparticles, Pharmaceutical and biological evaluations., 2016, 3, 327-333.

28. Snyder, S. A.; Adham, S.; Redding, A. M.; Cannon, F. S.; Decarolis, J.; Oppenheimer, J.; Wert, E. C. \& Yoon, Y., Role of membranes and activated carbon in the removal of endocrine disruptors and pharmaceuticals, Desalination., 2007, 202, 156-181.

29. Song, Z.Y.; Xiao, w.; Hao, J.; Cui, Y.Z.; Lv, I. H. \& Min, B. G., Kinetics and Thermodynamics of Sodium Alginate/Hydroxyapatite Composite Adsorption Fiber for Cd (II) Adsorping. Materials Science Forum, Trans Tech Publ., 2013, 578-583.

30. Ternes, T. A.; Meisenheimer, M.; Mcdowell, D.; Sacher, F.; Brauch, H.-J.; Haist-gulde, B.; Preuss, G.; Wilme, U. \& Zulei-seibert, N., Removal of pharmaceuticals during drinking water treatment, Environmental science \& technology., 2002, 36, 3855-3863.

31. Winker, M.; Faika, D.; Gulyas, H. \& Otterpohl, R., A comparison of human pharmaceutical concentrations in raw municipal wastewater and yellowwater, Science of the total environment., 2008, 399, 96-104.

32. Yaneva, Z. \& Koumanova, B., . Comparative modelling of mono-and dinitrophenols sorption on yellow bentonite from aqueous solutions, Journal of colloid and interface science., 2006, 293, 303-311. 